\title{
RESENHA
}

DOI: https://doi.org/10.22481/praxis.v15i31.4685

\section{ARTE, ATIVIDADE DE ENSINO E O DESENVOLVIMENTO DA CAPACIDADE CRIATIVA NA EDUCAÇÃO ESCOLAR}

\author{
ART, TEACHING ACTIVITY AND THE DEVELOPMENT OF CREATIVE \\ CAPACITY IN SCHOOL EDUCATION
}

\section{ARTE, ACTIVIDAD DE ENSENAANZA Y EL DESARROLLO DE LA CAPACIDAD CREATIVA EN LA EDUCACIÓN ESCOLAR}

\author{
Thiago Xavier de Abreu \\ Universidade Estadual Paulista - Brasil \\ Universidade Estadual de Ponta Grossa - Brasil
}

\begin{abstract}
RESUMO
Resenha sobre o livro A criatividade na arte e na educação escolar: uma contribuição à pedagogia histórico-crítica à luz de Georg Lukács e Lev Vigotski, de Maria Cláudia da Silva Saccomani.
\end{abstract}

Palavras-chave: Arte. Criatividade. Educação Escolar.

\section{ABSTRACT}

Review of the Creativity in art and school education: a contribution to Historical Critical Pedagogy in the light of Georg Lukács and Lev Vigotski, by Maria Cláudia da Silva Saccomani.

Keywords: Art. Creativity. School education.

\section{RESUMEN}

Reseña sobre el libro La creatividad en el arte y en la educación escolar: una contribución a la pedagogía histórico-crítica a la luz de Georg Lukács y Lev Vigotski, de Maria Cláudia da Silva Saccomani.

Palabras clave: Art. Creatividad. Educación Escolar.

A perspectiva de que a atividade educacional deva estimular a criatividade do indivíduo tornou-se quase um senso comum e, como tal, necessita ser compreendida pela ciência para além de sua aparência superficial. Esse é o intuito do livro A criatividade na arte e na educação escolar: uma contribuição à pedagogia histórico-crítica à luz de Georg Lukács e Lev Vigotski, de Maria Cláudia da Silva Saccomani, lançado em 2016 pela Editora Autores Associados (Campinas/SP), que, apesar de seu título, extrapola em muito o âmbito 
das discussões restritas aos fundamentos da pedagogia histórico-crítica e ao ensino da arte. A obra abrange desde a crítica a algumas concepções presentes no atual cenário educacional até a proposição de uma noção de criatividade organicamente ligada à especificidade do ensino escolar, tomando, em ambos, a arte como objeto do debate. De acordo com a autora, trata-se de "analisar as relações entre a transmissão da cultura acumulada e o desenvolvimento da criatividade na arte e na educação escolar", "em um esforço para ir além de dicotomias muito presentes nos discursos pedagógicos contemporâneos, como as oposições entre criação e reprodução, construção e transmissão do conhecimento, inovação e conservação, entre outras" (SACCOMANI, 2016, p. 4).

O livro é estruturado em três capítulos, encaminhados da problematização crítica à proposição teórica. O primeiro capítulo, denominado A contraposição entre ensino $e$ criatividade nas pedagogias do "aprender a aprender", apresenta uma análise do posicionamento pedagógico no qual a criatividade é tratada como um atributo intrínseco ao ser humano ou como resultante de interações espontâneas entre o indivíduo e a cultura, dispensando, assim, a transmissão sistematizada de conhecimento. Dessa maneira, formula-se aqui a problemática cuja presente obra pretende superar: a ideia de que o ensino é uma atividade antagônica ao desenvolvimento da criatividade.

O capítulo 2 do livro busca fundamentos teóricos para um trabalho educativo que apreenda dialeticamente as relações entre o ensino dos conteúdos escolares e o fenômeno criativo, analisando a gênese histórica da criatividade. Seu título, $O$ desenvolvimento histórico-social da criatividade, expõe com precisão a tese central do segmento: a criatividade é um aspecto da atividade humana que se desenvolve historicamente exatamente por meio dessa atividade.

Para esta discussão, Saccomani se apoia principalmente em dois teóricos, cujos fundamentos gerais se inserem no âmbito do materialismo histórico-dialético: o psicólogo Lev Vigotski e o filósofo Georg Lukács. Vigotski, bem como outros autores da psicologia histórico-cultural, auxiliam na compreensão do tema da criação do prisma dos processos psicológicos nele envolvidos. Questões como o papel da imaginação como função do psiquismo humano e a definição vigotskiana da arte como técnica social do sentimento, isto é, como instrumento cultural criado para atribuir existência objetiva aos sentimentos, são examinadas pela autora. Já a contribuição de Lukács se dá pela via do entendimento do fenômeno artístico, bem como do papel específico da atividade criativa neste fenômeno. Saccomani explica a ideia central da estética lukacsiana da obra de arte como reflexo 
mimético da realidade (reflexo não mecânico ou que não se constitui como mera cópia), apontando a categoria de catarse como um elemento essencial para a compreensão da relação entre a obra de arte e o indivíduo, observando as especificidades do processo criativo nessa relação.

Por fim, no terceiro capítulo, intitulado A criatividade na pedagogia histórico-crítica, Saccomani busca expressar uma concepção de criatividade que se alinhe à especificidade historicamente constituída da educação escolar: a socialização dos conhecimentos sistematizados (SAVIANI, 2008, 2009; SAVIANI, DUARTE, 2012). Daí a necessidade da superação da contraposição entre ensino e criatividade por uma perspectiva positiva das relações entre estes processos, uma vez que ensinar está na própria essência do que seja a instituição escolar.

Para o cumprimento desse objetivo, Saccomani recorre à aproximação de ideias de três diferentes teóricos. Primeiramente, a autora aborda as relações entre automatismo e liberdade analisadas por Dermeval Saviani. Em suma, trata-se da noção de que uma ação realmente livre só pode partir do que é dominado e internalizado, portanto, automatizado, tornado uma segunda natureza deste indivíduo. Tal concepção é estudada à luz da psicologia com o apoio da obra de Alexei Leontiev, notadamente seus estudos sobre a formação das operações conscientes. Esses conteúdos são aproximados da questão da arte pela discussão acerca da segunda imediatez contida na obra de Georg Lukács: a ideia de que a relação "natural", "espontânea", "inconsciente", "imediata" com a qual o indivíduo lida com a arte, tanto em sua criação quanto em sua recepção, é, na verdade, formada socialmente.

O livro ainda conta com o prefácio de Lígia Márcia Martins, que destaca sua “adequação metodológica nos marcos do materialismo histórico-dialético, no que tange à construção do conhecimento, questão nem sempre clara para quem principia pesquisas à luz desse aporte filosófico" (p. xii). Em outras palavras, Martins considera a obra uma importante contribuição aos pesquisadores que se valem deste referencial teórico-metodológico, pois, para ela, trata-se de um rico exemplo de aplicação metodológica. Newton Duarte assina o posfácio $O$ conceito dialético de reprodução e a pedagogia histórico-crítica, onde explora a seguinte pergunta: "haveria lugar na pedagogia histórico-crítica para o conceito de reprodução?” (p. 201). Partindo dessa questão, o autor discute uma concepção dialética de reprodução, isto é, como, ao mesmo tempo, conservação do existente e criação do novo, além de apontar as implicações educacionais dessa perspectiva. 
Tendo em vista a exposição aqui realizada, percebe-se que $A$ criatividade na arte e na educação escolar: uma contribuição à pedagogia histórico-crítica à luz de Georg Lukács e Lev Vigotski pode colaborar significativamente em diferentes campos da pesquisa e da prática educacional, especialmente no que tange ao ensino das artes. Na área da educação musical, por exemplo, sua pertinência é evidente. O estímulo da capacidade criativa foi elevado, no século $\mathrm{XX}$, ao próprio objetivo da atividade pedagógica da música, como nas propostas educacionais de Carl Orff, George Self, John Paynter, Murray Schafer, entre outros (ABREU, 2014; 2018; FONTERRADA, 2008; MATEIRO, ILARI, 2011). Por outro lado, Maura Penna (1999, 2004) e Rosa Fuks (1991) já apontavam a fragilidade pedagógica do "movimento chamado criatividade", isto é, das "práticas pedagógicas que enfatizam o espontaneísmo expressivo, caindo muitas vezes no mais puro laisser-faire, trazendo como consequência o esvaziamento dos conteúdos próprios da linguagem artística” (PENNA, 1999, p. 60). Nesse sentido, a análise empreendida por Saccomani pode fornecer subsídios para a investigação dessas problemáticas, na medida em que aprofunda em temas como o "espontaneísmo" e a importância dos conteúdos escolares para o fazer criativo.

Contudo, mais do que questionar modelos hegemônicos, o livro de Maria Cláudia da Silva Saccomani é propositivo. Um trabalho de amplo espectro, que une uma rigorosa leitura crítica à aproximação de autores fundamentais da psicologia, filosofia e pedagogia, com a finalidade de auxiliar no desenvolvimento de um aporte teórico que entenda profundamente as relações entre arte, criatividade e escola. Uma importante contribuição para as atividades pedagógicas comprometidas com a transformação da realidade.

\section{REFERÊNCIAS}

ABREU, Thiago Xavier de. EPHTAH!: das ideias pedagógicas de Murray Schafer. 01/07/2014. 199p. Dissertação (Mestrado em Música). Instituto de Artes da UNESP, São Paulo, 01 de julho de 2014. Orientadora: Prof ${ }^{a}$. Dr ${ }^{\mathrm{a}}$. Marisa Trench de Oliveira Fonterrada.

ABREU, Thiago Xavier de. Música e Educação Escolar: contribuições da estética marxista e da pedagogia histórico-crítica para a educação musical. Tese (Doutorado em Educação). UNESP - Universidade Estadual Paulista - FCLAr, Araraquara, 10 de agosto de 2018. Orientador: Prof. Dr. Newton Duarte.

FONTERRADA, Marisa Trench de Oliveira. De tramas e fios: um ensaio sobre música e educação. São Paulo: Editora Unesp, 2008.

FUCKS, Rosa. O discurso do silêncio. Rio de Janeiro: Enelivros, 1991. 
MATEIRO, Teresa; ILARI, Beatriz (org.). Pedagogias em Educação Musical. Curitiba: Ibpex, 2011.

PENNA, Maura. Ensino da Arte: momento de transição. Revista Pro-Posições, Campinas, v. 10, n. 3 (30), pp. 57-66, nov. 1999. Disponível em: <<

http://www.proposicoes.fe.unicamp.br/proposicoes/textos/30-artigos-pennam.pdf $>>$ Acessado em: 12/11/2014 às 11:00.

PENNA, Maura. A dupla dimensão da política educacional e a música na escola: I analisando a legislação e termos normativos. Revista da ABEM, Porto Alegre, n. 10, pp. 1828, mar. 2004.

SACCOMANI, Maria Cláudia da Silva. A criatividade na arte e na educação escolar: uma contribuição à pedagogia histórico-crítica à luz de Georg Lukács e Lev Vigotski. Campinas: Autores Associados, 2016.

SAVIANI, Dermeval. Pedagogia histórico-crítica: primeiras aproximações. $10^{\mathrm{a}} \mathrm{ed}$. Campinas: Autores Associados, 2008.

SAVIANI, Dermeval. Escola e democracia, 41 ${ }^{\text {a }}$ ed. Campinas: Autores Associados, 2009.

SAVIANI, Dermeval; DUARTE, Newton. Pedagogia histórico-crítica e luta de classes na educação escolar. Campinas: Autores Associados, 2012.

\section{SOBRE O AUTOR:}

\section{Thiago Xavier de Abreu}

Doutor em Educação pela Universidade Estadual Paulista (UNESP); membro do grupo de pesquisa Estudos Marxistas em Educação da UNESP/FCLAr; Professor Colaborador no curso de Licenciatura em Música da Universidade Estadual de Ponta Grossa (UEPG). E-mail: parathiagoxavier@gmail.com 